\title{
The Requirements of Initiating a Mangosteen Supply Chain Management in Banyuwangi District, Indonesia
}

\author{
Retno Astuti ${ }^{*}, 1$ Mas'ud Effendi ${ }^{1}$, Sucipto ${ }^{1}$, Wignyanto ${ }^{1}$ \\ ${ }^{1}$ Department of Technology of Agricultural Industry, Faculty of Agricultural Technology \\ Universitas of Brawijaya, Jl. Veteran, Malang 65145, East Java, Indonesia. \\ Email: retno_astuti@ub.ac.id
}

\begin{abstract}
In order to have competitive advantages, a supply chain management in Mangosteen business should be initiated in Banyuwangi Distric, East Java Indonesia. The aim of this research was to identify the requirements of initiating a Mangosteen supply chain management in Banyuwangi District and analyze the relationships between the requirements. Interpretative Structural Modeling was used to describe the relationships between the requirements of the chain. The availability of capital was the priority requirements to be fulfilled in initiating a Mangosteen supply chain management in Banyuwangi District.
\end{abstract}

Keywords: Interpretative Structural Modeling, Mangosteen, Supply Chain Management.

\section{INTRODUCTION}

Mangosteen (Garcinia mangostana L.) is a highly demanded fruit for export commodity from Indonesia. export volume of Mangosteen increased $153 \%$ or US \$ 13.7 million during January-May 2015 comparing to the same period in 2014 (Ministry of Trade 2015). Export of Mangosteen contributed in average $25.5 \%$ of exported fruit from Indonesia (Directorate General of Horticulture, 2014). One of the Mangosteen centres in Indonesia is Banyuwangi District, East Java. The activities of Mangosteen production for export market in the area have not been efficient yet to compete internationally, as the farmers only have small scale farms which are located in various places and are managed individually, and there is a lack of farmer skill in maintaining their farms and in managing the Mangosteen business.

Previous research had suggested that the strategy to win the global competition should include enhancement of the cooperation between business partners and all-out effort to meet customer demands (Marimin, et al., 2010). In order to have competitive advantages in facing the market demand and consumers' preference, a Mangosteen, supply chain management in Mangosteen business should be initiated in Banyuwangi District which will integrate processes from receiving raw materials to sell finished products. Requirements identification in initiating a Mangosteen supply chain management in Banyuwangi District are necessary to be carried out to improve the efficiency and effectiveness of the Mangosteen business. In running its business processes, the members of the chain should be linked between each other and the supply chain requirements should also be linked with each other. The objectives of this study are to identify the requirements of initiating a Mangosteen supply chain management in Banyuwangi District and analyse the relationships between the requirements.

\section{MATERIAL AND METHODS}

Initiating a more integrated supply chain management of mangosteen business in Banyuwangi District will increase the complexity of the business system because decision making situations involve many interacting causes and effects. Individual or a group can deal more effectively with systems and make better decisions concerning systems when the structure of the system is well defined. ISM (Interpretive Structural Modeling) is a process that helps individuals or groups of people in structuring their collective knowledge and it refers to the systematic application of graph theory in such a way that theoretical, conceptual, and computational leverage is exploited to efficiently construct a directed graph, or network representation, of 
the complex pattern of a contextual relationship among a set of elements (Prasanna and Ramanna, 2014). In other words, it helps to identify structure within a system of related elements. In this research, the requirements relationships in initiating a Mangosteen supply chain management in Banyuwangi District is clarified and analyzed using ISM.

The supply chain management of Mangosteen in Banyuwangi District have not been initiated so that it has limitation in data availability to achieve minimal sample size requirement when using statistical methodology. ISM is subjective methods with experts judgements as the main data used those are not necessary to involve a large sample. A small sample (in this case are representative expert judgements) is useful for research focusing on a specific issue where a large sample is not mandatory (Cheng and Li 2002). Furthermore, ISM allows decision makers to model a complex problem in a structure portraying the relationships of the alternatives requirements.

In order to clarify the requirements relationship of initiating a Mangosteen supply chain management in Banyuwangi District, experts who represent members of chain or those who have expertise in Mangosteen business, are asked to list the requirements considered affecting the chain. Initial study is carried out with experts to determine the initial criteria pool by a thorough literature review and doing qualitative interviews. A purposive sample is used to ensure the representation of experts within each member of the supply chain. In this research, 7 experts are selected from which 1 represent farmers, 1 represents farmers group, 1 represents collector, 1 represents supplier, 1 represents retailer, 1 represents exporter, and 1 represents Agricultural Office of Banyuwangi District. A comprehensive literature review is conducted to ground the development of the initial pool of items. Experts then review the initial pool of criteria and give feedback regarding criteria relevance, clarity, conciseness, and sufficiency in tapping the constructs. A contextual relationship then is established among the requirements with respect to which pairs of the requirements will be examined.

In order to express the relationships between the requirements of initiating a
Mangosteen supply chain management in Banyuwangi District, four symbols have been used to denote the direction of relationships between the requirements $i$ and $\mathrm{j}$ (here $\mathrm{i} \neq \mathrm{j}$ ) as follow:

$\mathrm{V}$ : The requirements $\mathrm{i}$ will help to fulfill the requirements $\mathrm{j}$

A: The requirements $j$ will be fulfilled by the requirements

$\mathrm{X}$ : The requirements $\mathrm{i}$ and $\mathrm{j}$ will help to fulfill each other

$\mathrm{O}$ : The requirements $\mathrm{i}$ and $\mathrm{j}$ are unrelated.

The next step is developing a structural self-interaction matrix (SSIM) which indicate pairwise relationships among the requirements of the chain. Based on the adjacent matrix, a reachability matrix (a binary matrix which elements are 0 or 1 ) that reflects the directed relationship between the requirements, is created then the matrix is checked for transitivity (Warfield, 1976). The rules for the substitution of 1's and 0's are as follows:

- If the $(i, j)$ entry in the SSIM is $V$, then the $(i, j)$ entry in the reachability matrix becomes 1 and the $(j, i)$ entry becomes 0 .

- If the $(i, j)$ entry in the SSIM is $A$, then the $(i, j)$ entry in the reachability matrix becomes 0 and the $(j, i)$ entry becomes 1 .

- If the $(i, j)$ entry in the SSIM is $X$, then the $(i, j)$ entry in the reachability matrix becomes 1 and the $(j, i)$ entry also becomes 1

- If the $(i, j)$ entry in the SSIM is $O$, then the $(i, j)$ entry in the reachability matrix becomes 0 and the $(j, i)$ entry also becomes 0 .

In the final reachability matrix, the driver power and the dependence of each requirement are also shown. The driver power for each requirement is the total number of requirements (including it) which it may impact. Dependence of requirement is the total number of requirements (including it) which may be impacting on it. These driver powers and dependencies will be used in the MICMAC (Matrice d'Impact Croisés Multiplication Appliqueé à un Classement or Matrix of Cross Impact - Multiplications Applied to Classification) analysis (Godet 1986), where the requirements will be classified into four groups - autonomous, dependent, linkage, and independent (driver) requirements. Based on the relationship given 
in the reachability matrix, a directed graph is drawn and the transitive links are removed then the resultant digraph is converted into an ISM. The ISM then is reviewed to check for conceptual inconsistency and necessary modifications are made to clarify the relationships among the requirements.

\section{RESULTS}

According to the opinion of Mangosteen business participants, the requirements of initiating Mangosteen supply chain management are (1) The quality and quantity assurance of Mangosteens which are ready to be sold to export market; (2) The quality and quantity assurance of Mangosteens harvested from farmers' orchard in Banyuwangi District; (3) The availability of facilities and infrastructure; (4) The qualified human resources; (5) The availability of capital; (6) The availability of technology; and (7) The increased revenue of Mangosteen business stake-holders The relationship between the requirements of initiating a Mangosteen supply chain management in Banyuwangi District then is analyzed based on the opinions of experts using ISM which help to identify structure within a system of related elements (Eriyatno 2002). Based on this contextual relationship, an initial SSIM is developed as shown in Table 1.

Table 1. Initial SSIM for the Requirements of Initiating a Mangosteen Supply Chain Management in Banyuwangi District

\begin{tabular}{c|ccccccc}
\hline $\mathbf{j}$ & $\mathbf{1}$ & $\mathbf{2}$ & $\mathbf{3}$ & $\mathbf{4}$ & $\mathbf{5}$ & $\mathbf{6}$ & $\mathbf{7}$ \\
\hline $\mathbf{1}$ & & $\mathrm{A}$ & $\mathrm{A}$ & $\mathrm{A}$ & $\mathrm{A}$ & $\mathrm{A}$ & $\mathrm{V}$ \\
$\mathbf{2}$ & & & $\mathrm{A}$ & $\mathrm{A}$ & $\mathrm{A}$ & $\mathrm{A}$ & $\mathrm{V}$ \\
$\mathbf{3}$ & & & & $\mathrm{X}$ & $\mathrm{A}$ & $\mathrm{X}$ & $\mathrm{V}$ \\
$\mathbf{4}$ & & & & & $\mathrm{A}$ & $\mathrm{X}$ & $\mathrm{V}$ \\
$\mathbf{5}$ & & & & & & $\mathrm{V}$ & $\mathrm{V}$ \\
$\mathbf{6}$ & & & & & & & $\mathrm{V}$ \\
$\mathbf{7}$ & & & & & & & \\
\hline
\end{tabular}

Based on the adjacent matrix, a reachability matrix (a binary matrix which elements are 0 or 1), that reflects the directed relationship between the requirements, is created then the matrix is checked for transitivity. Following the rules for the substitution of 1's and 0's and after incorporating the transitivity, the final reachability matrix is created. Once the transformation from SSIM to initial reachability matrix has been carried out according to the rules, any transitive links that may exist between different requirements are investigated. In the final reachability matrix, the driving power and the dependence of each requirement are shown (Table 2 ).

Table 3. Reachability Matrix Interpretation for the Requirements of Initiating Mangosteen Supply Chain Management in Banyuwangi District

\begin{tabular}{|c|c|c|c|c|c|c|c|c|c|}
\hline$i^{\mathbf{j}}$ & 1 & 2 & 3 & 4 & 5 & 6 & 7 & $D P$ & $\boldsymbol{R}$ \\
\hline 1 & 1 & 0 & 0 & 0 & 0 & 0 & 1 & 2 & 4 \\
\hline 2 & 1 & 1 & 0 & 0 & 0 & 0 & 1 & 3 & 3 \\
\hline 3 & 1 & 1 & 1 & 1 & 0 & 1 & 1 & 6 & 2 \\
\hline 4 & 1 & 1 & 1 & 1 & 0 & 1 & 1 & 6 & 2 \\
\hline 5 & 1 & 1 & 1 & 1 & 1 & 1 & 1 & 7 & 1 \\
\hline 6 & 1 & 1 & 1 & 1 & 0 & 1 & 1 & 6 & 2 \\
\hline 7 & 0 & 0 & 0 & 0 & 0 & 0 & 1 & 1 & 5 \\
\hline$D$ & 6 & 5 & 4 & 4 & 1 & 4 & 7 & & \\
\hline $\boldsymbol{R}$ & 2 & 3 & 4 & 4 & 5 & 4 & 1 & & \\
\hline $\begin{array}{l}D P \\
R: 1\end{array}$ & $9 r$ & & we & & & & & & \\
\hline
\end{tabular}

The reachability matrix then is used to make Driving power - Dependence diagram (Figure 1) which is used in the MIC-MAC analysis to analyze the driving power and the dependence of the requirements of initiating a Mangosteen supply chain management in Banyuwangi District. The reachability matrix is also decomposed into different levels to create a structural model diagram of the requirements of initiating a Mangosteen supply chain management in Banyuwangi District which provided a multilevel ISM (Figure 2).

\section{DISCUSSION}

Structural model diagram of the requirements of initiating a Mangosteen supply chain management in Banyuwangi District shows that the availability of capital is the priority requirements to support the initiating of a Mangosteen supply chain management in Banyuwangi District. The availability of capital can be fulfilled if the supply chain involved institutions that have strong driving power to provide that requirement. Involvement of banking institutions/financial, 
NGOs / facilitators, governments, and investors can support the availability of capital

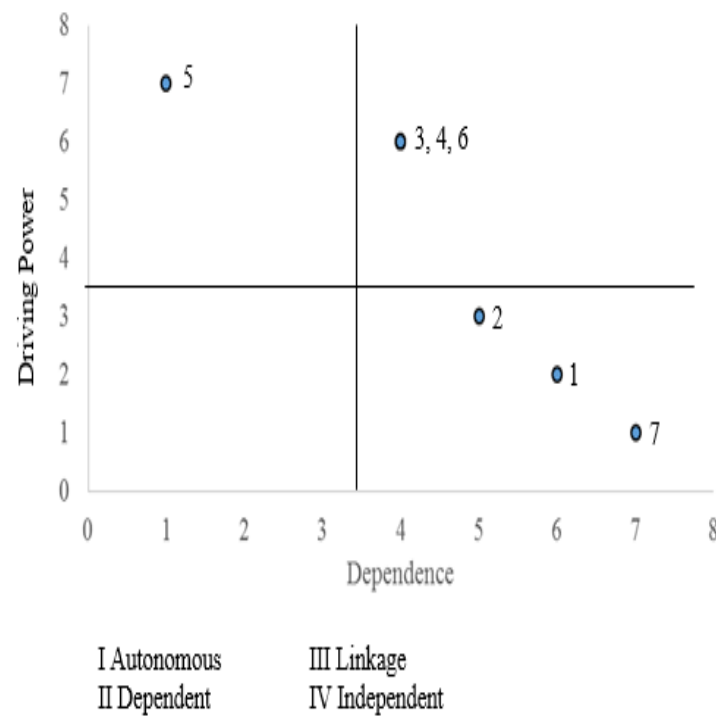

Figure 1. DP-D diagram

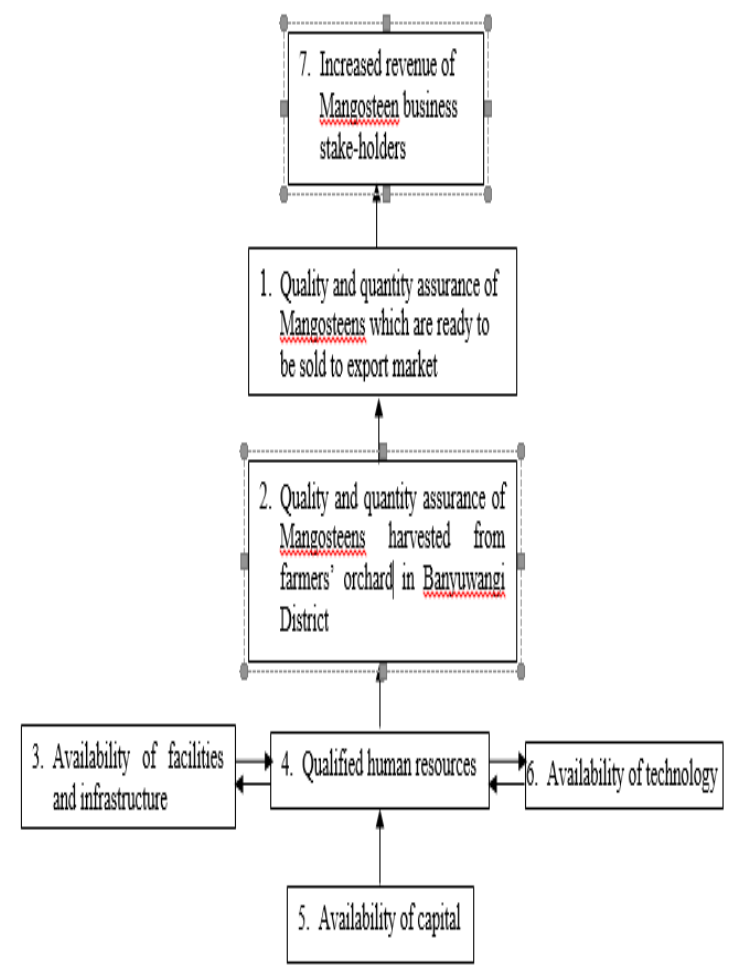

Figure 2. Structural model diagram of the requirements of initiating a Mangosteen supply chain management in Banyuwangi District

The availability of capital have a high driving power to meet other requirements of initiating a Mangosteen supply chain management in Banyuwangi District. It also does not depend on other requirements (high driving power and low dependence as shown in DP-D diagram). If the capital is available, then the qualified human resources, the availability of technology, and the availability of facilities and infrastructure will be achieved.

According to Ferroni and Castle (2011), small farmers in developing countries generally have limited access to technology, extension services, and market integration. This condition also occurs in a small Mangosteen farmers in Banyuwangi District that cannot meet the demands of export markets such as the continuity of quantity, quality, food safety and competitive prices. The Mangosteen farmers can get extension service on cultivation technology and some post-harvest technology and training to improve their skill in Mangosteen cultivation and business from Agricultural Office of Banyuwangi District. Research institutes / universities also can support the member of Mangosteen supply chain to meet those requirements, but the result of training and extension cannot be applied optimally due to the lack of facilities and infrastructure. So, facilities and infrastructure are also required to initiate a Mangosteen supply chain management in Banyuwangi District. Infrastructure and facilities can be obtained through coordination with the government or other investors.

The availability of technology, facilities and infrastructure, and qualified human resources will support each other to assure the quality and quantity of Mangosteens harvested from farmers' orchard in Banyuwangi District. Those requirements depend on the availability of capital, but have a high driving power. Quality and quantity assurance of Mangosteens harvested from farmers' orchard in Banyuwangi District are required to make a sustainable Mangosteen supply chain.

If the Mangosteen supply chain management can assure the quality and quantity of Mangosteens harvested from farmers' orchard in Banyuwangi District, then the quality and quantity of Mangosteens which are ready to be sold to export market will also be assured. This requirement is also required by the Mangosteen supply chain management in Banyuwangi District to have a high competitive advantage internationally. If Mangosteen business in Banyuwangi District 
can compete internationally, then the stakeholders of Mangosteen business will get increased revenue which will increase the value added of Mangosteen. This increased value added should be distributed among the stake-holders fairly to create fair business (Bunte, 2006) so the Mangosteen supply chain will be sustainable.

\section{CONCLUSIONS}

A Mangosteen supply chain management should be initiated in Banyuwangi District, East Java, Indonesia to improve competitive advantage of the Mangosteen for export market and run Mangosteen business more effectively and efficiently. The availability of capital is the priority requirement to be fulfilled in initiating Mangosteen supply chain management in Banyuwangi District. This requirement have a high driving power to achieve the availability of technology, facilities and infrastructure, and qualified human resources then all together will assure the quality and quantity of Mangosteens harvested from farmers' Mangosteen crops in Banyuwangi District and ready to be sold to export market. The revenue of Mangosteen business stake-holders will increase if all the requirements of initiating Mangosteen supply chain management in Banyuwangi District are fulfilled.

\section{REFERENCES}

Bunte, F. 2006. Pricing and Performance in Agri-Food Supply Chains in Quantifying the Agri-food Supply Chain. (pp. 37-45). (Editors: Ondersteijn, C.J.M., Wijnands, J.H.M., Huirne, R.B.M,. and Van Kooten, O.). Netherlands:Springer.

Cheng, E.W.L and Li, H. 2002. Construction Partnering Process and Associated Critical Success Factors: Quantitative Investigation, Journal of Management in Engineering, 18 (4):194-202.

Directorate General of Horticulture. 2014. Description of Macro Performance of Horticulture. Jakarta: Agricultural Ministry.

Eriyatno. 2002. System Knowledge, Improving Management of Quality and Effectivity. Bogor: IPB Press.
Ferroni, M. and Castle. P. 2011. Public-Private Partnerships and Sustainable Agricultural Development. Sustainability, 3(7):10641073

Godet, M. 1986. Introduction to $\mathrm{La}$ Prospective: Seven Key Ideas and One Scenario Method. Futures, 18 (2):134-157.

Marimin, Feifi, D., Martini, S., Astuti, R., Suharjito, and Hidayat, S. 2010. Added Value and Performance Analyses of Edamame Soybean Supply Chain: A Case Study. Operations and Supply Chain Management, 3(3):148-162.

Ministry of Trade. 2015. The Trend of Exported Mangosteen. (http://www. kemendag.go.id). Accessed on July 31, 2015

Prasanna, S.V.S.N.D.L and Ramanna, T.R. 2014. Application of ICT Benefits for Building Project Management using ISM. International Journal of Research in Engineering and Technology, 3(6):320-324

Warfield, J.N. 1976. Societal systems: planning, policy and complexity. New York: John Wiley \& Sons Inc. 